\title{
Case report of unusual cause of lower GI bleeding
}

\author{
Bader Al-Hadhrami*, Nadyia Al-Harthi, and Abd Elrafea Elkak \\ Royal Hospital, Muscat, Oman
}

\begin{abstract}
Lower GI bleeding is a challenging emergency for the gastroenterologist and the surgeon especially when it is massive and obscure in origin. We present a case of a 41 years old male who presented to our hospital with lower GI bleeding which was massive and of unknown origin. It necessitated taking the patient for surgical intervention. The patient was found to have a bleeding gastrointestinal stromal tumor (GIST) in the small bowel. Small bowels GISTs are rare and unusual to present with lower GI bleeding.
\end{abstract}

\section{Case summary}

41 years old gentleman known to have neurofibromatosis type 1 who, in the past, underwent surgery of frontal brain lobe xanthoastrocytoma presented to the local hospital with massive rectal bleeding where he was resuscitated and referred to our center for further investigations and management. The patient was haemodynamyically reasonably stable when he was received in our centre with a hemoglobin of 9 $\mathrm{g} / \mathrm{dL}$, He continued to have rectal bleeding and an urgent upper gastrointestinal endoscopy and colonoscopy was arranged which did not identify the source of bleeding. Abdomen CT angiogram and then a mesenteric CT angiogram were performed but neither showed active contrast extravasation which could explain the source of bleeding. The CT showed extensive cutaneous and subcutaneous neurofibromatosis and left iliacus neurofibromatosis. The patient was kept on a high dependency unit where he received further 2 units of blood and his haemoglobin was stable around $9 \mathrm{~g} / \mathrm{dl}$. However, he became restless and drowsy and so he was intubated that stage and shifted to intensive care where he received further 2 units of blood and his haemoglobin did rise marginally from $8 \mathrm{~g} / \mathrm{dL}$ to $8.2 / \mathrm{dL}$, He continued to be off inotropes but tachycardic $>110$. So, the patient continued to pass P.R bleeding and was decided to be taken for surgical control. At laparotomy, there was a fairly vascular small bowel tumor $50 \mathrm{~cm}$ from ileocecal junction with no intraluminal blood distal to it. Another smaller one tumor was found just proximal to the first one (Figure 1). The first tumor was segmentally resected and continuity of the bowel was restored with side to side hand sewn anastomosis whilst the second tumor was locally excised. The patient remained stable in the postoperative period and made a swift recovery so he was discharged home after 5 days and seen in the clinic and found to have no complains. The Histopathology of the resected tumors came back as gastrointestinal stromal tumor (GIST) low malignant potential. With good margins $>5 \mathrm{~cm}$ free of the disease. Then the Patient was referred to medical oncologist for further input. He was seen after 2 months from the surgery in the medical oncology with a CT of chest, abdomen and pelvis which was normal and started on imatinib and he still in Follow-up with them.

\section{Discussion}

There is a cohort of causes of lower GI bleeding which had been described in the medical literature (Table 1). These causes may vary with the age and other associated conditions. Our patient was a known case of neurofibromatosis type 1 (NF-1). This condition in particular may have some rare gastrointestinal manifestations.

NF-1 is inherited as autosomal dominant with complete penetrance and variable expression [1]. The frequency of intra-abdominal (gastrointestinal or retroperitoneal) manifestations of NF-1 varied greatly in previous studies ranging from 5\%-25\% [1].

GIST is a rare neoplasm accounting for about $1 \%-3 \%$ of all malignant neoplasms of the gastrointestinal tract. These tumors bear certain histopathological similarities to a specific cell type inherent in the GI tract, known as interstitial cells of Cajal (ICC) [2]. The majority of GIST cases (60\% to $70 \%$ ) arise from stomach. GIST tumours have been classified to myogenic, neurogenic and non-differentiated tumours [3].

Gastrointestinal manifestations of NF-1 usually arise during midlife or later; generally later than the appearance of the cutaneous manifestations of the disease. In a study from a large specialized centre,

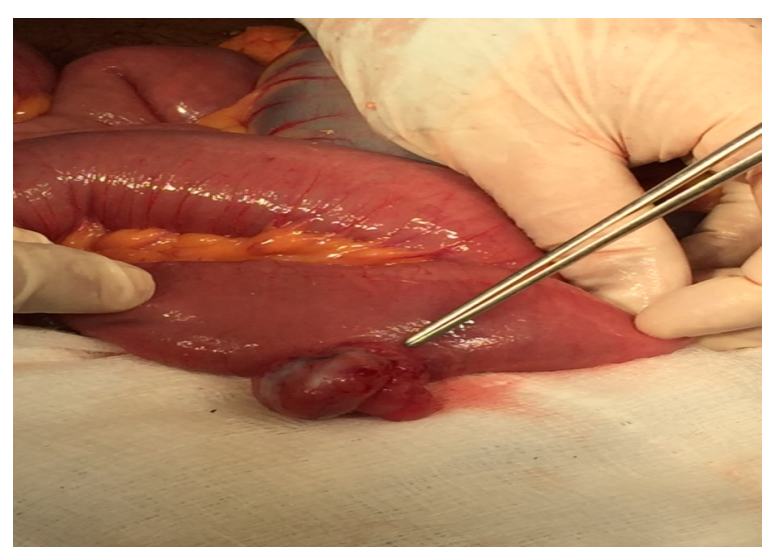

Figure 1. GIST of the ileum as seen intraoperatively

Correspondence to: Bader Al-Hadhrami, MD, Royal Hospital, Muscat, Oman, E-mail: drbader85@hotmail.com

Received: March 04, 2016; Accepted: March 25, 2016; Published: March 28, 2016 
Table 1. Causes of Lower GI Bleeding.

\begin{tabular}{|l|l|l|l|}
\hline Benign Conditions & Inflammatory Conditions & Malignant Conditions \\
\hline $\begin{array}{l}\text { Diverticulosis/Diverticultitis } \\
\text { Meckel's diverticulum }\end{array}$ & Ulcerative colitis & Colorectal Cancers & Vascular Conditions \\
\hline Polyps/Hemorrhoids & Crohn's disease & $\begin{array}{l}\text { Small Bowel tumors (adenocarcinomas, } \\
\text { Carcinoids and GIST) }\end{array}$ & AV malformations \\
\hline Fissure in Ano & Non-infective colitis & Metastases to Lower GIT \\
\hline Trauma & Infective coloitis & Post-Radoitherapy & Dieulafoy's disease \\
\hline
\end{tabular}

intra-abdominal (gastrointestinal or retroperitoneal) manifestations necessitating surgical intervention occurred in $2.5 \%$ of patients, at a median age of 40 years, followed up regularly [3,4]. NF1 patients may be predisposed to developing small intestinal GISTs, which may appear as multiple GISTs [5].

The GIST tumour in our case was a rare manifestation of uncommon condition of neurofibromatosis as a cause of massive lower GI bleeding. It had been reported in the literature that such condition is rare cause of obscure lower GI bleeding. The cases reported were mainly jejunal GISTs which mainly presented as obscure lower GI bleeding long lasting for weeks [6]. Our patient was different in the sense that he presented acutely with significant lower GI bleeding that required a surgical intervention and his GISTs were in the ileum.

There are some reports that GISTs have been increasingly documented as an abdominal manifestation of the disease. GISTs were detected in $25 \%$ of NF-1 patients at autopsy $[7,8]$. Thus, they represent the most common gastrointestinal manifestation of NF-1 reported in literature.

However taken by site, NF-1 associated GISTs represented 6\%, $4 \%$ and $0.06 \%$ of duodenal jejuno-ileal and gastric GISTs at the AFIP respectively. The mean age at GIST diagnosis was 49 years compared to a mean age of 56 years for small bowel GISTs in genera l. Most NF-1 associated GISTs present as small asymptomatic lesions with low mitotic activity and they generally follow a benign clinical course $[8,9]$.

There has been a growing number of literature reporting an association between NF1 and GIST [10]. The malignancy is commonly determined by the tumor size and the mitotic ratio. Tumours larger than $5 \mathrm{~cm}$ in diameter or having a mitotic count greater than 5 per high-power field are classified as malignant [11-13]. In our case, the tumour was $3 \mathrm{~cm}$ in maximum diameter and with a low potential of malignancy as the mitotic figure was $5 / 50$. Surgical resection is the treatment of choice. Lesions $>2 \mathrm{~cm}$ should be resected. Lesions $<2 \mathrm{~cm}$ can be monitored with serial imaging. Medical management involves treatment with Imatinib, which interferes with tumour proliferation by disrupting signalling via the C-kit oncogene [14].

\section{Conclusion}

Neurofibromatosis type 1 is an uncommon condition which may be present with lower GI bleeding and it should alert the surgeon for possibility of associated GIST tumor as a rare manifestation of such condition. There had been literature reports which described such lesions as a cause of lower GI bleeding [10-12], one of the rarest tumors is GIST. To our knowledge in this country (Oman) our case is the first case of such manifestation of NF and GIST of small bowel presented with massive lower GI bleeding.

\section{References}

1. Ferner RE (2007) Neurofibromatosis 1 and neurofibromatosis 2 : a twenty first century perspective. Lancet Neurol 6: 340-351. [Crossref]
2. Perez-Atayde AR, Shamberger RC, Kozakewich HW (1993) Neuroectodermal differentiation of the gastrointestinal tumors in the Carney triad. An ultrastructural and immunohistochemical study. Am J Surg Pathol 17: 706-714. [Crossref]

3. Bagnolo F, Bonassi U, Scelsi R, Testoni PA (1998) Gastric stromal tumour: a rare neoplasm presenting with gastrointestinal bleeding. Eur J Gastroenterol Hepatol 10: 791-794. [Crossref]

4. Agaimy A, Vassos N, Croner RS (2012) Gastrointestinal manifestations of neurofibromatosis type 1 (Recklinghausen's disease): clinicopathological spectrum with pathogenetic considerations. Int J Clin Exp Pathol 5: 852-862. [Crossref]

5. Basile U, Cavallaro G, Polistena A, Giustini S, Orlando G, et al. (2010) Gastrointestinal and retroperitoneal manifestations of type 1 neurofibromatosis. J Gastrointest Surg 14: 186-194. [Crossref]

6. Cavallaro G, Basile U, Polistena A, Giustini S, Arena R, et al. (2010) Surgical management of abdominal manifestations of type 1 neurofibromatosis: experience of a single center. Am Surg 76: 389-396. [Crossref]

7. Nishida T, Tsujimoto M, Takahashi T, Hirota S, Blay JY, et al. (2015) Gastrointestinal stromal tumors in Japanese patients with neurofibromatosis type I. J Gastroenterol 41 378-382. [Crossref]

8. Agaimy A, Vassos N, Croner RS (2012) Gastrointestinal manifestations of neurofibromatosis type 1 (Recklinghausen's disease): clinicopathological spectrum with pathogenetic considerations. Int J Clin Exp Pathol 5: 852-862. [Crossref]

9. Agaimy A, Märkl B, Kitz J, Wünsch PH, Arnholdt H, et al. (2010) Peripheral nerve sheath tumors of the gastrointestinal tract: a multicenter study of 58 patients including NF1-associated gastric schwannoma and unusual morphologic variants. Virchows Arch 456: 411-422. [Crossref]

10. Zöller ME, Rembeck B, Odén A, Samuelsson M, Angervall L (1997) Malignant and benign tumors in patients with neurofibromatosis type 1 in a defined Swedish population. Cancer 79: 2125-2131. [Crossref]

11. Miettinen M, Fetsch JF, Sobin LH, Lasota J (2006) Gastrointestinal stromal tumors in patients with neurofibromatosis 1: a clinicopathologic and molecular genetic study of 45 cases. Am J Surg Pathol 30: 90-96. [Crossref]

12. Valencia E, Saif MW (2014) Neurofibromatosis type 1 and GIST: is there a correlation? Anticancer Res 34: 5609-5612. [Crossref]

13. Pidhorecky I, Cheney RT, Kraybill WG, Gibbs JF (2000) Gastrointestinal stromal tumors: current diagnosis, biologic behavior, and management. Ann Surg Oncol 7: 705712. [Crossref]

14. An uncommon cause of overt obscure gastrointestinal bleeding. Dr. Sean O’LoghlenPGY-2 Queen's University Ted Giles Clinical Vignettes 2015 CSIM Annual Meeting Charlottetown, PEI, Canada.

Copyright: (C2016 Al-Hadhrami B. This is an open-access article distributed under the terms of the Creative Commons Attribution License, which permits unrestricted use, distribution, and reproduction in any medium, provided the original author and source are credited. 